\title{
Are we ready for cosmetic surgery on aortic arches after Norwood?
}

From the Department of Cardiac Surgery, Royal Children's Hospital, Melbourne, Victoria, Australia; the Department of Paediatrics, University of Melbourne, Melbourne, Victoria, Australia; and the Murdoch Childrens Research Institute, Melbourne, Victoria, Australia.

Disclosures: Authors have nothing to disclose with regard to commercial support.

Received for publication Oct 12, 2018; accepted for publication Oct 12, 2018; available ahead of print Nov 27 , 2018.

Address for reprints: Yves d'Udekem, MD, PhD, FRACS, 50 Flemington Rd, Parkville, Victoria 3052, Australia (E-mail: yves.dudekem@rch.org.au).

J Thorac Cardiovasc Surg 2019;157:696-8

$0022-5223 / \$ 36.00$

Copyright $\subset 2018$ by The American Association for Thoracic Surgery

https://doi.org/10.1016/j.jtcvs.2018.10.080

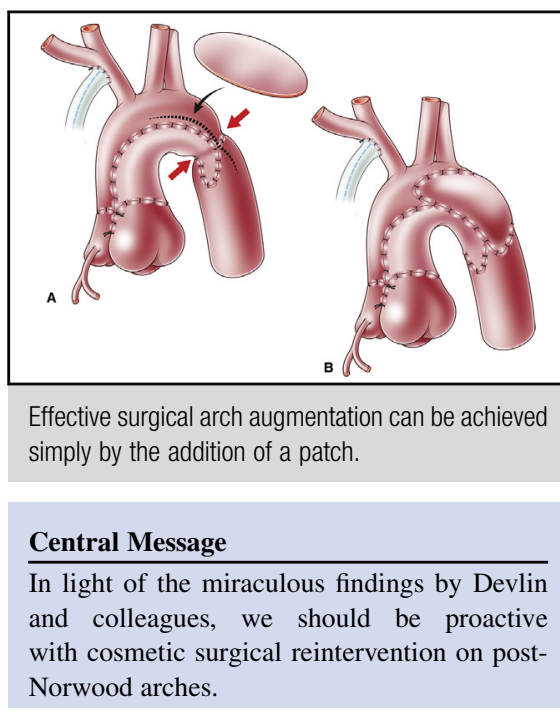

See Article page 684
After nearly 4 decades of Norwood procedures, the chance for salvation of our patients depends on achieving the holy trinity of an unobstructed arch, competent atrioventricular valve and normal ventricular function. Between one-quarter and one-half of patients undergoing a Norwood procedure at most institutions will require arch reintervention. So the issue faces us all, but we are still unclear on how to prevent it, the ideal procedure to address it, and the threshold at which we should intervene. The miraculous work in this issue of the Journal by Devlin and colleagues ${ }^{1}$ analyzing outcomes of 593 patients from the Congenital Heart Surgeons' Society database provides some enlightenment. Miraculous, because the complexity of the analysis (multiphase parametric hazard analysis with multivariable modulated renewal models, time-varying covariables, multiple imputation and bootstrap aggregation) will mystify most of us!

\section{HOW TO PREVENT IT?}

The potential for recurrent arch obstruction should be in our minds at the primary operation. In the analysis of Devlin and colleagues, ${ }^{1}$ an interdigitating arch anastomosis ${ }^{2}$ protected against subsequent reintervention (11\% vs $25 \%$ with and without interdigitation). Not all patients may need this precise technique, but clearly complete resection of ductal tissue is not enough, and radical strategies to enlarge the area are needed.

\section{WHAT PROCEDURE?}

The series of Devlin and colleagues ${ }^{1}$ clearly demonstrates that surgical reintervention provides longer lasting results with no added mortality. The majority of reinterventions $(77 \%)$ were catheter based, and in a modulated renewal analysis Devlin and colleagues showed that balloon dilatation predisposed to recurrent intervention, whereas surgery was protective. In Melbourne, we have found reoperation on the arch to be straightforward and effective (Figure 1). ${ }^{3}$ We systematically perform the second stage when the patient reaches 3 months of age, ${ }^{4}$ and the added arch work does not seem to add morbidity to the procedure. Obviously, patients with a failing circulation far from their secondstage procedure may benefit from a transcatheter intervention.

\section{WHEN TO INTERVENE?}

Reintervention in the current era does not adversely impact long-term mortality. So, should we touch-up these arches because we can? Yes, probably. We cannot yet determine the long-term adverse impact of residual arch obstruction on late outcomes in patients with a single ventricle, but it seems logical to believe that such obstruction would be consequential. In an examination of data from the Australia and New Zealand Fontan Registry, we determined that having an arch reintervention was linked to a higher rate of adverse events (Figure 2), ${ }^{5}$ a finding that we attributed to the likelihood of residual arch lesions. Devlin and colleagues ${ }^{1}$ clearly 

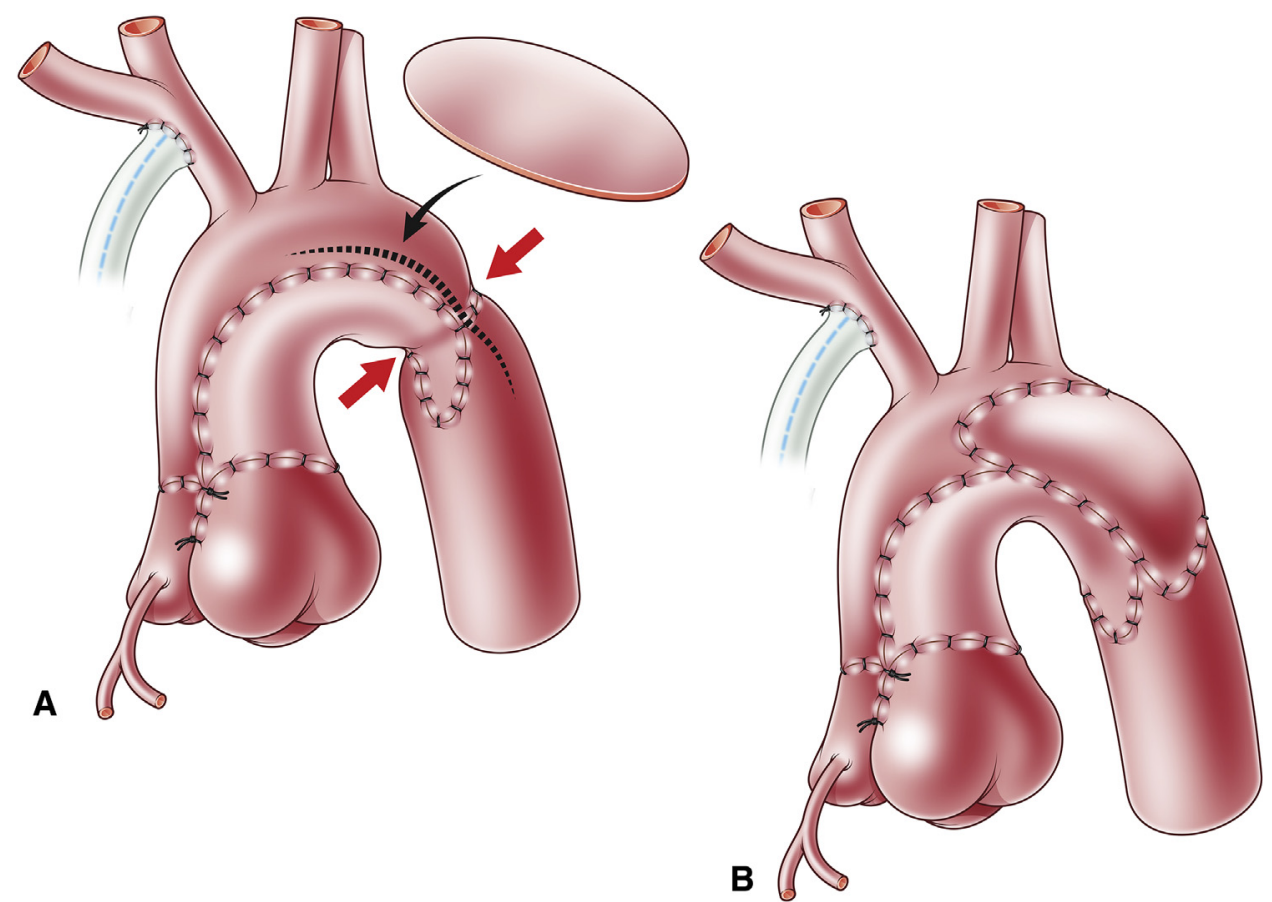

FIGURE 1. Effective surgical arch augmentation can be achieved simply by the addition of a patch. A, An incision is made across the obstruction in the axis of the aorta. B, After patch augmentation.

demonstrate the association between residual arch lesions and worse tricuspid valve and ventricular function, and this relationship is undoubtedly causal. The current threshold at which reintervention is warranted remains poorly defined, and it will remain poorly defined, because in a single-ventricular circulation, arch obstruction is likely to impair cardiac output before it generates a high gradient. Our personal take from the article of Devlin and colleagues ${ }^{1}$ is that we should not hesitate to intervene early_and surgically-on residual arch lesions after Norwood. We should intervene on all arches that seem to have a suboptimal shape or

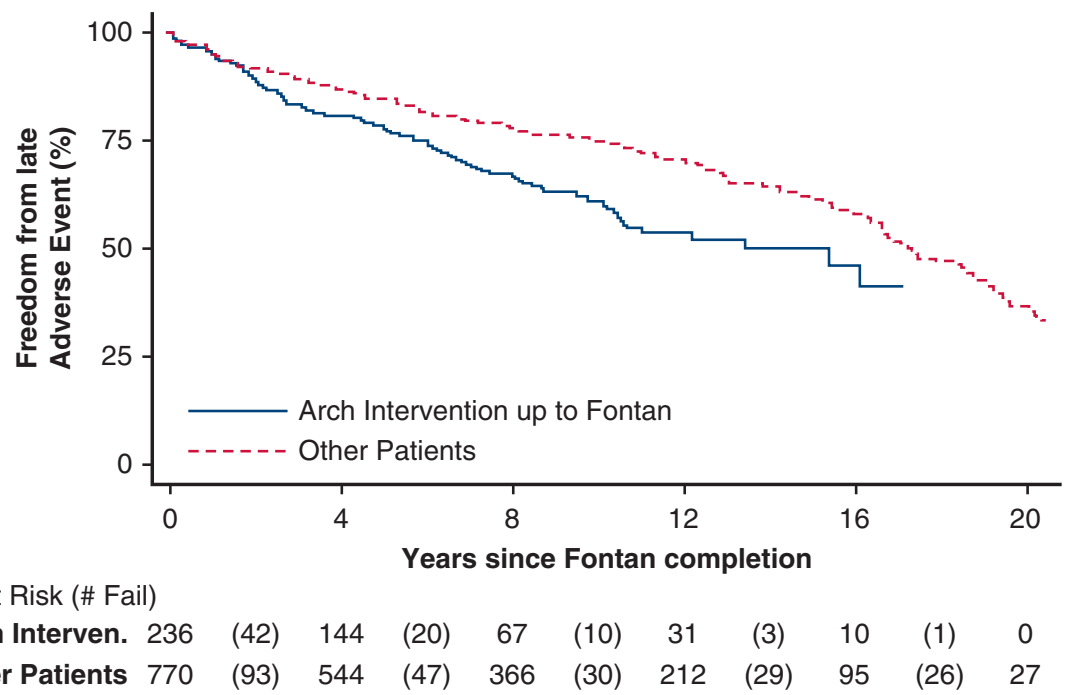

FIGURE 2. Arch reintervention up to and including the time of Fontan operation is associated with an increased risk of adverse events (death, takedown, transplantation, supraventricular tachycardia, thromboembolism, or pacemaker implantation) after the Fontan operation, likely because these patients have historically been treated late or left with residual obstruction. Data from the Australian and New Zealand Fontan Registry. ${ }^{4}$ 
size: it is time for cosmetic surgery on aortic arches after Norwood!

\section{References}

1. Devlin PJ, McCrindle BW, Kirklin JK, Blackstone EH, DeCampli WM, Caldarone CA, et al. Intervention for arch obstruction after the Norwood procedure: prevalence, associated factors, and practice variability. J Thorac Cardiovasc Surg. 2019;157:684-95.e8.

2. Burkhart HM, Ashburn DA, Konstantinov IE, De Oliveira NC, Benson L, Williams WG, et al. Interdigitating arch reconstruction eliminates recurrent coarctation after the Norwood procedure. J Thorac Cardiovasc Surg. 2005;130:61-5.
3. Lee MG, Brizard CP, Galati JC, Iyengar AJ, Rakhra SS, Konstantinov IE, et al. Outcomes of patients born with single-ventricle physiology and aortic arch obstruction: the 26-year Melbourne experience. J Thorac Cardiovasc Surg. 2014;148:194-201.

4. Jones BO, Ditchfield MR, Cahoon GD, Hardy P, d'Udekem Y, Brizard CP, et al. Cardiac magnetic resonance imaging prior to bidirectional cavopulmonary connection in hypoplastic left heart syndrome. Heart Lung Circ. 2010;19: 535-40.

5. d'Udekem Y, Iyengar AJ, Galati JC, Forsdick V, Weintraub RG, Wheaton GR, et al. Redefining expectations of long-term survival after the Fontan procedure: twenty-five years of follow-up from the entire population of Australia and New Zealand. Circulation. 2014;130(11 Suppl 1):S32-8. 